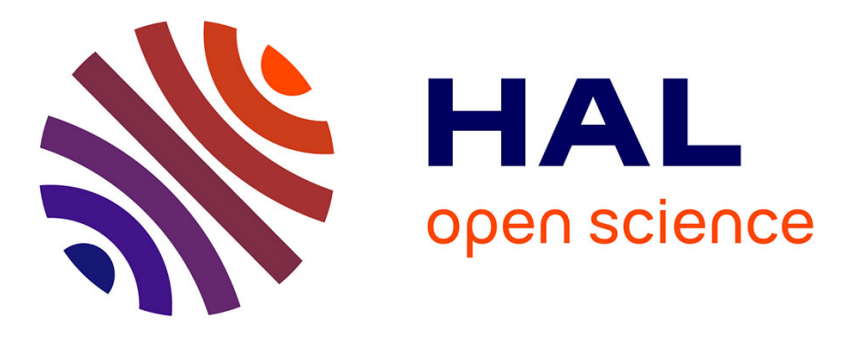

\title{
Nuclear magnetic resonance and ionic motion in fluorozirconate glasses
}

\author{
S. Estalji, R. Küchler, O. Kanert, R. Bölter, H. Jain, K. Ngai
}

\section{To cite this version:}

S. Estalji, R. Küchler, O. Kanert, R. Bölter, H. Jain, et al.. Nuclear magnetic resonance and ionic motion in fluorozirconate glasses. Journal de Physique IV Proceedings, 1992, 02 (C2), pp.C2-159-C2163. 10.1051/jp4:1992221. jpa-00251292

\section{HAL Id: jpa-00251292 https://hal.science/jpa-00251292}

Submitted on 1 Jan 1992

HAL is a multi-disciplinary open access archive for the deposit and dissemination of scientific research documents, whether they are published or not. The documents may come from teaching and research institutions in France or abroad, or from public or private research centers.
L'archive ouverte pluridisciplinaire HAL, est destinée au dépôt et à la diffusion de documents scientifiques de niveau recherche, publiés ou non, émanant des établissements d'enseignement et de recherche français ou étrangers, des laboratoires publics ou privés. 


\title{
Nuclear magnetic resonance and ionic motion in fluorozirconate glasses
}

\author{
S. ESTALJI, R. KÜCHIER, O. KANERT, R. BÖLTER, H. JAIN *,(1) and K. L. NGAI ${ }^{* *}$ \\ Institut für Physik, Universität Dortmund, 4600 Dortmund 50, Germany \\ ${ }^{*}$ Department of Materials Science and Engineering, Lehigh University, Bethlehem, PA 18015, U.S.A. \\ ${ }^{* *}$ Naval Research Laboratory, Washington, DC 20375, U.S.A.
}

\begin{abstract}
We have determined NMR linewidths and nuclear spin relaxation rates for ${ }^{19} \mathrm{~F}$, ${ }^{7} \mathrm{Li}$, and ${ }^{23} \mathrm{Na}$ nuclei, and electrical conductivity in $\mathrm{ZrF}_{4}$-based fluoride glasses as a function of temperature. The results indicate that both Li and $F$ are mobile in the glass containing 20 mole\% LiF, whereas only $F$ is mobile in glasses containing $\mathrm{NaF}$ (up to 30 mole\%) or no alkali ions. Finally we compare and discuss the activation energies for the various parameters.

\section{RESUME'}

Des mesures de conductivité électrique et de $\mathrm{RMN}$ de ${ }^{19} \mathrm{~F},{ }^{7} \mathrm{Li}$ et ${ }^{23} \mathrm{Na}$ ont éte realisées sur des verres fluorures à base de $\mathrm{ZrF}_{4}$ : les variations des largeurs de raies de resonance et des temps de relaxation ont eté étudiees en fonction de la temperature. Les résultats demontrent que les ions $\mathrm{Li}$ et $F$ sont mobiles dans le verre contenant $20 \%$ de LiF(en fraction molaire). Dans le cas des verres contenant du NaF(jusqu'à $30 \%$ en mole) ou ne contenant pas de cation alcalin. seul lion $F$ est mobile. Les énergies d'activation deduites des divers parametres sont comparées et analysées.
\end{abstract}

\section{INTRODUCTION}

The $\mathrm{ZrF}_{4}$-based fluoride glasses were originally reported to be fluoride ion conductors/1/. However, when alkali ions are also present these glasses become mixed cation-anion conductors; the relative contribution of the cations and anions being dependent on the concentration and nature of the alkali ion/2.3/. In this context nuclear magnetic resonance (NMR) techniques have been proven to be very useful, for example, by demonstrating that only a fraction of $F$ contributes to ionic conduction $/ 2,4,5 /$. At present there are two interesting questions on this subject: (a) how does the $F$ anion movement compare with the alkali movement? (b) Do conductivity and NMR perceive ion movement in the same way? The first question has been addressed in the references mentioned above, but a rigorous answer to the second question has been sought only recently/6/. In this report we present data on six glasses which elucidate these questions further.

\section{EXPERIMENTAL.}

The experiments were performed on six $\mathrm{ZrF}_{4}$-based glasses listed in Table 1. ${ }^{19} \mathrm{~F},{ }^{7} \mathrm{Li}$ and ${ }^{23} \mathrm{Na}$ nuclear spin relaxation (NSR) rates were measured using a modified Bruker SXP $4-100$ coherent pulsed NMR spectrometer. The NSR rates in the laboratory frame. $1 / T_{1}$, were measured by a $\pi-\tau-\pi / 2$ pulse 
sequence, while those in the rotating frame $\left(1 / T_{1 p}\right)$ were observed by the spinlocking technique. In $T_{10}$-experiments the value of the spin-locking field $B_{1}$ was chosen such that the effective Larmor frequency was $28 \mathrm{kHz}$ to $62 \mathrm{kHz}$. The linewidth for the same three nuclei was determined from the off-resonance free induction decay after Fourier transformation. The electrical conductivity was measured in the frequency range of $10 \mathrm{~Hz}$ to $100 \mathrm{kHz}$ using a 1620 General Radio ac bridge assembly.

Table 1 Composition of fluorozirconate glasses (in mol\%)

\begin{tabular}{l|c|c|c|c|c|c|c} 
Glass & $\mathrm{ZrF}_{4}$ & $\mathrm{HfF}_{4}$ & $\mathrm{BaF}_{2}$ & $\mathrm{LaF}_{3}$ & $\mathrm{AlF}_{3}$ & LiF & NaF \\
\hline ZBLALi(II) & 50.53 & - & 21.43 & 4.44 & 3.38 & 20.24 & - \\
ZBLAN(II) & 27.43 & 27.4 & 19.76 & 3.06 & 3.19 & - & 19.19 \\
ZBLA(II) & 59.45 & - & 30.87 & 5.69 & 3.99 & - & - \\
ZBLAN10 & 59.62 & - & 22.5 & 4.5 & 3.38 & - & 10 \\
ZBLAN20 & 53 & - & 20 & 4 & 3 & - & 20 \\
ZBLAN30 & 46.37 & - & 17.5 & 3.5 & 2.63 & - & 30
\end{tabular}

RESULTS

The temperature dependence of ${ }^{19} \mathrm{~F}$ and ${ }^{23} \mathrm{Na}$ linewidths in ZBLAN20, and of ${ }^{19} \mathrm{~F}$ and ${ }^{7} \mathrm{Li}$ linewidths in $\mathrm{ZBLALi}(\mathrm{II})$ glasses are shown in Figs.la,b. For both glasses ${ }^{19} \mathrm{~F}$ linewidth shows a sudden decrease upon heating above a particular temperature which represents the onset of motional narrowing when the linewidth becomes comparable with the $F$ jump rate. The temperature dependence of linewidth in the motional narrowing region has been analyzed following Hendrickson and Bray/7\%. The best fits to data are shown by the solid lines with the condition from theory that the linewidth approaches zero at sufficiently high temperatures. The activation energies calculated from various motional narrowing data, E , $_{\delta}$, are listed in Table 2 .
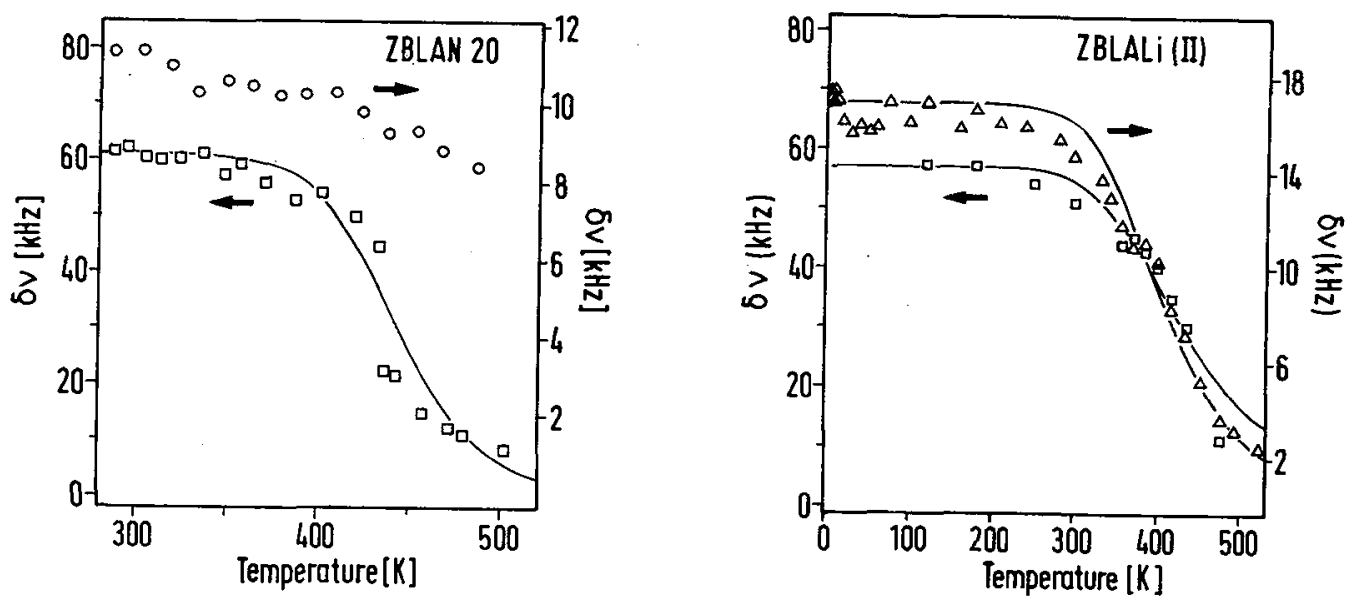

Figs. 1a,1b Linewidth of ${ }^{19} \mathrm{~F}(0)$ and ${ }^{23} \mathrm{Na}(\mathrm{o})$ in $\mathrm{ZBLAN} 20$ (left figure) and of ${ }^{19} \mathrm{~F}(\square)$ and ${ }^{7} \mathrm{Li}(\Delta)$ in $\mathrm{ZBLaLi}(\mathrm{II})$ (right figure) as a function of temperature. Solid lines are based on theory $/ 7 \%$.

In this paper we are interested only in the NSR rate due to the ion diffusion which becomes effective for relaxing the spins at about room temperature and above/8/. That is, to obtain diffusion-induced NSR rate the low temperature background contribution are to be subtracted from the total observed NSR rates. The temperature dependences of the so corrected NSR rates are shown in 


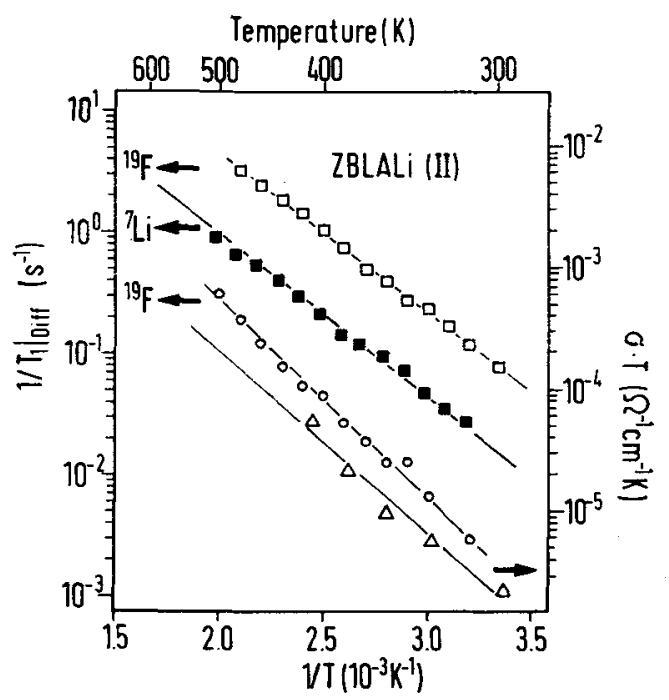

Fig.2 ${ }^{19} \mathrm{~F}$ and ${ }^{7} \mathrm{Li}$ NSR-rates, 1/ $\mathrm{T}_{1} \mathrm{Diff}$, in ZBLALi(II) for Larmor frequencies $15 \mathrm{MHz}(\mathrm{Q}) ; 251 \mathrm{MHz}(0) ; 69.5 \mathrm{MHz}(\bullet)$ $\Delta$ denote extrapolated conductivity data (see text)

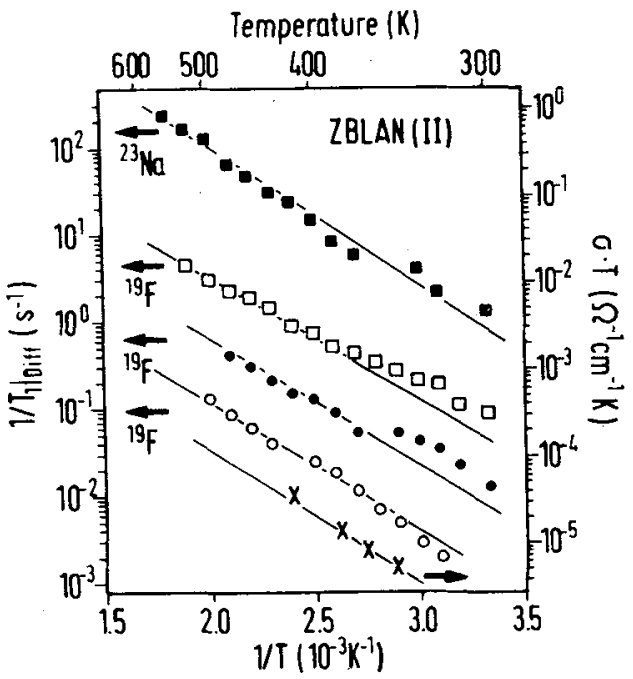

Fig. $3{ }^{19} \mathrm{~F}$ and ${ }^{23} \mathrm{Na} \mathrm{NSR}$-rates, $1 / \mathrm{T}_{1}$ Diff, in ZBLAN(II) for Larmor frequencies $15 \mathrm{MHz}(\mathrm{O}) ; 56.5 \mathrm{MHz}(\bullet) ; 251 \mathrm{MHz}(0)$; $70 \mathrm{MHz}(\boldsymbol{*}) ; \quad x$ denote extrapolated conductivity data (see text)

Figs. 2 and 3 for ZBLALi(II) and ZBLAN(II) glasses, respectively, for various nuclei and Larmor frequencies. Note that the NSR rates increase with temperature in an Arrhenius fashion from which we have obtained respective activation energies $\left(E_{T_{1}}\right)$ as listed in Table 2. The magnitude of the relaxation rates depends on Larmor frequency $\omega_{0}$ as $\sim \omega_{0}{ }^{-\beta}$ where $\beta=1.1 \pm 0.1$. These NSR rates in laboratory frame are obtained at Larmor frequencies which are one or more orders of magnitude higher than the highest frequency of ac conductivity measurements. Therefore, to have a common frequency in the two techniques, NSR rates have been measured in the rotating frame with lower effective frequencies. Results of these measurements on ZBLAN(II) glass are shown in Fig. 4 for three different effective frequencies. Note that at such frequencies it has been possible to observe the maximum in NSR rate below the glass transition temperature. The low and high temperature sides of the peak give activation energies $E_{T_{10}}(0.26 \pm 0.02)$ $\mathrm{eV}$ and $E_{T_{10}}=(0.76 \pm 0.1)$ eV, respectively. Within the experimental error $E_{T_{1}}$ is the same for all the three frequencies.

Finally, we have obtained dc conductivity odc for three glasses using complex impedance analysis. Plots of $\ln \left(\sigma_{\mathrm{dc}} \cdot \mathrm{T}\right)$ vs $1 / \mathrm{T}$, where $\mathrm{T}$ is the absolute temperature, give the activation energy $E_{d c}$ which is given in Table 2. However, we consider fixed frequency ac conductivity to compare with the NSR rate at the same frequency. This comparison is shown in Fig. 4 where $\sigma_{\text {ac }} \cdot \mathrm{T}$ at $30 \mathrm{kHz}$ is plotted vs $1 / T$.

\section{DISCUSSION}

From Fig. 1 we note that the motional narrowing of ${ }^{7} \mathrm{Li}$ and ${ }^{19} \mathrm{~F}$ occurs in the same temperature range. This is consistent with the previous observations that in $\mathrm{ZrF}_{4}$-based glasses containing 20 mole\% LiF both $\mathrm{Li}$ and F ions contribute to electrical conduction/2,3,5/. In contrast, for the sodium containing glasses $\left(\mathrm{NaF}=10\right.$ to $30 \mathrm{~mole} \%$ we observe motional narrowing primarily for ${ }^{19} \mathrm{~F}$ which should therefore be the predominant mobile species. The ${ }^{23} \mathrm{Na}$ linewidth decreases with increasing temperature but to a much smaller extent; this can be attributed simply to the motion of ${ }^{19} \mathrm{~F}$ ions. Thus we conclude that our sodium containing 
Fig. 4 Temperature dependence of ${ }^{19}$ F NSR in $Z B L A N(I I)$ in the rotating frame, $\left(1 / \mathrm{T}_{1 \rho}\right)$ Diff, for different effective Larmor frequencies: $28 \mathrm{kHz}(0)$; $42 \mathrm{kHz}(\bullet) ; 62 \mathrm{kHz}$ (口); denote conductivity data at $30 \mathrm{kHz}$

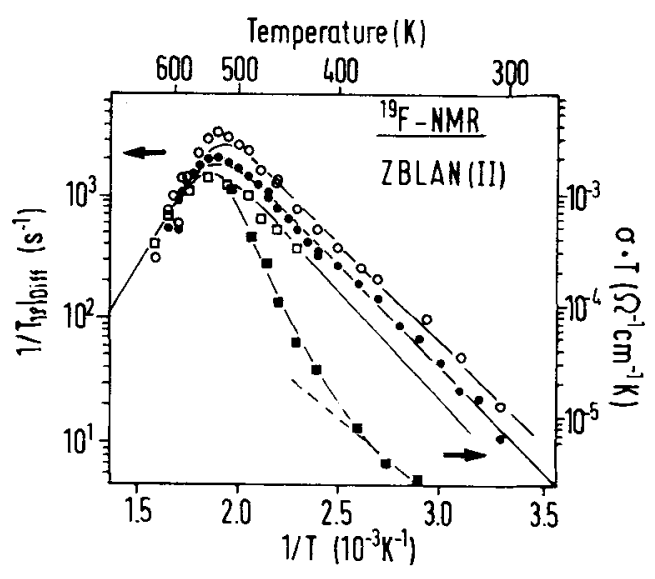

glasses remain primarily $F$ ion conductors. In our experimental method it has been difficult to resolve the ${ }^{19} \mathrm{~F}$ line into that due to mobile and immobile fluorine ions/4/. Nevertheless, the fact that there is a residual ${ }^{9} \mathrm{~F}$ linewidth even at the highest temperature suggests that some $F$ atoms never become mobile.

The obvious observation from the data for the first three glasses in Table 2 is that the activation energy for dc conductivity is about 3 times larger than $E_{1}$ or Esv: This is similar to a common feature found in oxide glasses/9/, and is believed to be a consequence of inter-particle interactions which also manifest as the power law dependence of conductivity on frequency. The values of ET, at various frequencies and $E_{\delta \nu}$ are the same for a given glass within experimentat error. In fact, we obtain the same activation energy $E_{\text {ac }} \mathrm{s}$ for fixed frequency ac conductivity in the range of tens of $\mathrm{MHz}$. For that we extrapolated conductivity data taken in the region between $10 \mathrm{~Hz}$ and $100 \mathrm{kHz}$ to the corresponding NMR Larmor frequencies(see Table 2). Therefore we conclude that for these three glasses both the NMR and ac conductivity are in the same dispersive region (where $\sigma \sim \omega s, s$ is a constant) of ion jump phenomenon/10/. At present for the last two glasses in Table 2 we do not have Edc data but we expect it to be comparable to the values for the first three glasses. Then we note that E $\delta \nu$ is similar in magnitude to $E_{d c}$ than to $E_{T}$. Clearly, in these glasses the linewidth experiment is conducted in a different frequency region than the $T_{1}$-experiment. The former should be in or around the Gaussian region (where o is frequency independent) whereas the latter continues to be in the dispersive region. It has been implicit in the above discussion that NMR and conductivity experiments perceive ion movement in the same way, the observed difference between the activation energies for the two phenomena is obviously caused by the different frequencies in the two experiments. Figure 4 offers a verification of this assump tion. Here we note that under the conditions of identical frequencies $E_{a c}$ seems to be equal to $E_{T_{1}}$ but only in a limited temperature region (below $400 \mathrm{~K}$; see dashed line in Fig.4). At higher temperature $E_{a c}$ approaches $E_{d c}$, whereas E $\mathrm{T}_{10}$ maintains its low value until reaching the maximum. We believe that this discre pancy occurs because $\sigma_{\text {ac }}$ encounters the Gaussian region of the frequency spectrum at a lower temperature than $1 / T_{1 \rho}$. Of course, on the high temperature side of the peak in figure 4 both $\sigma_{\text {ac }}$ and $1 / T_{1 \rho}$ are in the Gaussian region and the two have the same slope equal to $E_{d c}$. Thus we conclude that, in principle, NSR and conductivity depend on the same kind of ion movement but it is not necessary for the two phenomena to cross from dispersive to Gaussian regions at the same frequency. 
Table 2 Activation energies (in eV) for the six investigated glasses as calculated from nuclear spin relaxation and linewidth measurements for different nuclei and at different Larmor frequencies and activation energies from conductivity experiments.

\begin{tabular}{|c|c|c|c|c|c|c|c|c|c|c|}
\hline \multirow[b]{4}{*}{ Glass } & \multicolumn{6}{|c|}{$\underline{\mathbf{N M R}}$} & \multicolumn{2}{|c|}{ linewidth } & \multicolumn{2}{|c|}{ conductivity } \\
\hline & \multicolumn{5}{|c|}{$\frac{\text { Nuclear spin relaxation }}{{ }^{19} \mathrm{~F}}$} & \multirow{3}{*}{$\left|\begin{array}{c}{ }^{23} \mathrm{Na} \\
70 \mathrm{MHz} \\
\mathrm{ET}_{1}\end{array}\right|$} & ${ }^{7} \mathrm{Li}$ & ${ }^{19} \mathrm{~F}$ & \multirow[b]{3}{*}{$\mathbf{E}_{\mathrm{dc}}$} & \multirow[b]{3}{*}{$E_{a c}^{d i s p .}$} \\
\hline & $23 \mathrm{MHz}$ & $69 \mathrm{MHz}$ & $15 \mathrm{MHz}$ & $56 \mathrm{MHz}$ & $251 \mathrm{MHz}$ & & & & & \\
\hline & $\mathrm{E}_{\mathrm{T}_{1}}$ & $\mathrm{E}_{\mathbf{T}_{1}}$ & $\mathrm{E}_{\mathrm{T}_{1}}$ & $\mathrm{E}_{\mathrm{T}_{1}}$ & $\mathrm{E}_{\mathrm{T}_{1}}$ & & $\mathrm{E}_{\delta \nu}$ & $E_{\delta \nu}$ & & \\
\hline ZBLALi(II) & 0.28 & 0.27 & 0.27 & 0.28 & 0.31 & - & 0.3 & 0.26 & 0.89 & 0.29 \\
\hline ZBLAN(II) & & & 0.27 & 0.28 & 0.28 & 0.3 & - & - & 0.89 & 0.29 \\
\hline $\mathrm{ZBLA}(\mathrm{II})$ & & & 0.25 & 0.26 & 0.25 & - & - & - & 0.75 & 0.26 \\
\hline ZBLAN 10 & & & 0.24 & 0.24 & - & - & - & - & - & - \\
\hline ZBLAN 20 & & & 0.24 & 0.24 & - & - & - & 0.73 & - & - \\
\hline ZBLAN 30 & & & 0.24 & 0.24 & - & - & - & 0.74 & - & - \\
\hline
\end{tabular}

This work was supported by the Deutsche Forschungsgemeinschaft and by the U.S. Department of Energy (DE-FG o2-9oER 45419).

\section{REFERENCES}

/1/ Leroy, D, Lucas, J, Poulain, M and Ravaine,D, Mater. Res. Bull.13 (1978) 1125.

/2/ Kawamoto,Y, Fujiwara,J and Ichimura,C, J. Non-cryst.Solids $111(1989) 245$ and 124 (1990) 271

/3/ Zhao,X and Sakka,S, J. Non-cryst. Solids 99 (1988) 45

/4/ Bray,P.J, Hintenlang,D.E, Mulkern, R.V, Greenbaum, S.G, Tran, D.C and Drexhage, M, J. Non-cryst. Solids 56 (1983) 27

/5/ Senegas,J, Reau,J.M, Aomi,H, Hagenmuller, P and Poulain, M, J. Non-cryst. Solids 85 (1986) 315

/6/ Kanert, O, Küchler, R, Estalji,S, Ngai,K.L and Jain,H, Proc. VII Int. Conf. Phys. Non-cryst. Solids, Cambridge, England, August 1991 (in press)

17/ Hendrickson,J.R and Bray, P.J, J.Chem. Phys. 61 (1974) 2754

/8/ Estalji, S, Kanert, O, Steinert,J, Jain, H and Ngai,K.L, Phys. Rev. B $43(1991) 7481$

19/ Jain, H, Kanert, O and Ngai,K.L, Defect and Diffusion Forum $75(1991) 163$

/10/Kanert, O, Kloke, M, Kuchler, R, Rückstein, $S$ and Jain, H, Ber. Bunsenges.

Phys. Chem. 95 (1991) 1061 